AT - TADBIR

JURNAL ILMIAH MANAJEMEN

Homepage: ojs.uniska.ac.id/attadbir

\title{
Perancangan Atribut Produk Celana Denim Bobbiesjeans.Co Berdasarkan Preferensi Konsumen
}

\author{
Alan ramadhan*, Yati Rohayati, Wawan Tripiawan \\ Teknik Industri, Telkom University, Bandung, Jawa Barat \\ e-mail: alanramadhan@student.telkomuniversity.ac.id
}

\begin{abstract}
Bobbiesjeans.co is an SME in Bandung that is engaged in fashion and has been established since 2017. The main product sold by Bobbiesjeans.co is denim pants, this is supported by the percentage of sales of around 74\% compared to other products. The number of competitors who have more variations makes Bobbiesjeans.co denim pants products also experience ups and downs. Therefore, there is a need for innovation in Bobbiesjeans.co demin pants. The purpose of this study is to design the product attributes of Bobbiesjeans.co denim pants based on consumer preferences using the conjoint analysis method, product attributes for denim pants include model, material, color, leg opening width. Based on the results of the research that has been done, light blue can be added to the color. For the material, it is necessary to add a variety of poly denim (12 oz). Furthermore, for the waistline it is also necessary to add variations of low rise (below the waist) and mid rise (waist). Next to the model, it is necessary to add variations to the boot-cut model. And for arcuate it is also necessary to add variations of arcuate stitching.
\end{abstract}

Keywords: Product Attributes, consumer preferences, conjoint analysis, Bobbiesjeans.co, Denim

\begin{abstract}
Abstrak
Bobbiesjeans.co merupakan sebuah UMKM di Kota Bandung yang bergerak dibidang fashion dan sudah berdiri sejak tahun 2017. Produk utama yang dijual oleh Bobbiesjeans.co adalah celana denim, hal tersebut didukung dengan persentase penjualannya sekitar $74 \%$ dibanding produk lainnya. Banyaknya competitor yang memiliki variasi yang lebih banyak membuat produk celana denim Bobbiesjeans.co juga mengalami naik turun. Oleh karena itu perlu adanya inovasi dalam produk celana demin Bobbiesjeans.co. Tujuan dari penelitian ini adalah merancang atribut produk ceana denim Bobbiesjeans.co berdasarkan pada preferensi konsumen dengan menggunakan metode conjoint analysis, atribut produk untuk celana denim mencakup model, bahan, warna, lebar bukaan kaki. Berdasarkan hasil penelitian yang sudah dilakukan, untuk warna dapat ditambahkan warna light blue. Untuk bahan perlu ditambah variasi bahan poly denim (12 oz). Selanjutnya untuk waistline juga perlu ditambahkan variasi low rise (dibawah pinggang) dan mid rise (dipinggang). Berikutnya untuk model perlu ditambah variasi model boot-cut. Dan untuk arcuate juga perlu ditambahkan variasi stitching arcuate.
\end{abstract}

Kata Kunci: Atribut Produk, preferensi konsumen, conjoint analysis, Bobbiesjeans.co, Denim 


\section{PENDAHULUAN}

Perkembangan Industri pada bidang fashion saat ini sangat pesat dan digemari oleh semua kaum, khusunya kaum anak muda. Karena bagi mereka fashion sudah menjadi bagian dari gaya hidup zaman sekarang (Fathurahman et al., 2017). Hal ini didukung oleh pendapat Chaney (2004) dalam (Angela \& Paramita, 2020), seorang pakar fashion berkata, "Sementara dalam masyarakat modern, gaya hidup (lifestyle) membantu mendefinisikan mengenai sikap, nilai-nilai, kekayaan, serta posisi sosial seseorang".

Tidak mudah bagi para pelaku usaha yang bergerak di bidang fashion. Dengan banyak nya kompetitor yang menimbulkan terjadinya persaingan. Maka perusahaan dituntut untuk merancang startegi permasaran secara efektif, agar informasi tersebut langsung tersampaikan kepada konsumen. Untuk menanggapi persaingan bisnis fashion khususnya celana denim, maka aspek prefensi masyarakat sangat penting dimata pelaku usaha fashion (Wirapraja et al., 2021). Keberhasilan sebuah produk juga ditentukan oleh bagaimana produk itu dipasarkan serta bagaimana preferensi konsumen terhadap produk yang ditawarkan (Lestiyorini, 2015).

Preferensi konsumen akan selalu berubah dari waktu kewaktu, perubahan preferensi konsumen yang cepat sangat mempengeruhi pertumbuhan industry lifestyle. Perubahan dalam preferensi konsumen juga membuat strategi yang telah ditetapkan oleh perusahaan tudak dapat diterapkan secara optimal(Hameed et al., 2021). Perusahaan harus mampu mempertahankan kedudukannya dalam pasar dengan cara memenuhi kebutuhan dari konsumen. Perusahaan juga harus mampu memuaskan konsumen agar mendapatkan keuntungan yang lebih tinggi serta melampau target penjualan dengan cara banyak memberikan variasi serta inovasi produk dipasaran (Rahardjo, 2016).

Bobbiesjeans.co merupakan sebuah UMKM di Kota Bandung yang bergerak dibidang fashion dan sudah berdiri sejak tahun 2017. Produk utama yang dijual oleh Bobbiesjeans.co adalah celana denim, hal tersebut didukung dengan persentase penjualannya sekitar $74 \%$ dibanding produk lainnya. Pemesaran produk Bobbiesjeans.co dilakukan dengan offline store dan online store/marketplace seperti Shopee dan Tokopedia. Penjualan yang dilakukan oleh Bobbiesjeans.co untuk 1 tahun terakhir diketahui tidak menenuhi target penjualan. Hanya pada bulan mei 2020 yang melebihi target penjualannya 1250 produk dari target penjualan 1000 produk, ha ini didukung dengan adanya high season yakni even lebaran yang mana banyaknya konsumen yang mencari produk pakaian. Setelah bulan Mei Bobbiesjeans.co tidak dapat memenuhi target penjualannya. Dari pengamatan yang dilakukan diketahui bahwa terdapatnya adanya keluhan dari produksi celana jeans denim produksi Bobbiesjeans.co.

Pemilik Bobbiesjeans.co juga memberikan informasi terkait kegagalan pencapaian target yang salah satunya disebabkan oleh kelemahan dari produk celana denim Bobbiesjeans.co itu sendiri. Bobbiesjeans.co yang memberikan informasi mengenai keluhan dari produk celana denim Bobbiesjeans.co. Dengan adanya keluhan tersebut dapat mempengaruhi seseorang dalam membeli celana denim Bobbiesjeans.co, sehingga dapat dikatakan bahwa Bobbiesjeans.co masih belum memahami preferensi konsumen. Hal tersebut juga dapat mempengaruhi citra buruk terhadap celana denim dari Bobbiesjeans.co. Hal penting 
yang dapat mempengaruhi minat konsumen dalam membeli produk celana denim dari Bobbiesjeans.co adalah preferensi konsumen.

Oleh karena itu penelitian ini bertujuan untuk meidentifikasi preferensi konsumen terhadap atribut produk celana jeans pada Bobbijeans.co.

\section{TINJAUAN PUSTAKA}

Produk

Menurut Kotler \& Armstrong (2018), produk merupakan sesuatu yang daoat diberikan oleh perusahaan atau jasa kedalam pasar untuk memenuhi kebutuhan atau permintaan pasar, termasuk didalamnya berupa barang, layanan, pengalaman, peristiwa, lokasi, properti, organisasi, informasi, dan ide. Definisi lainnya dari produk adalah segala sesuatu yang mampu ditawarkan oleh produsen untuk dibeli dan digunakan oleh pasar sebagai bentuk dari pemenuhan kebutuhan(Pradana \& Reventiary, 2016).

Menurut (Disler et al., 2019) "product is asset of tangible and intangible attributes, including packaging, color, price quality and brand plus the services and reputation of the seller". Yang memiliki arti bahwa suatu produk merupakan kumpulan dari atribut-atribut yang nyata maupun tidak nyata, termasuk didalamnya berupa warna, harga, kualitas, merk, juga kemasan serta ditambah dengan jasa dan reputasi dari si penjualnya.

Menurut (Tjiptono \& Fandy, 2015))atribut produk merupakan unsur yang penting dan dijadikan sebagai acuan pembelian produk oleh konsumen, atribut produk meliputi merek, kemasan, jaminan (garansi), pelayanan. Menurut Kotler dan Armstrong (2009:214) beberapa atribut yang menyertai sebuah produk(karakteristik dari atribut produk) adalah:
Pertama, Merek (Branding) adalah nama, istilah, tanda, simbol, atau rancangan, atau kombinasi dari semua ini yang dimaksudkan untuk mengenali suatu barang atau jasa serta membedakannya dari produk pesaing. Pemberian sebuah merek pada produk merupakan hal yang sangat penting dalam menunjang pemasaran produk. Karena, apabia merek tersebut mudah dikenali maka akan menambah keberhasian sebuah produk itu.

Kedua, engemasan

(Packing) merupakan wadah dari sebuah produk, rancangan pengemasan yang menarik juga dapat menambah rasa ketertarikan dari konsumen.

Ketiga, Kualitas Produk (Product Quality) adalah kemampuan sebuah perusahaan agar mampu memberikan produk yang berkualitas serta mampu mempertahankan kualitas dari produk tersebut. Yang diantaranya meliputi daya tahan, ketepatan, kemudahan operasi, serta atribut bernilai yang lainnya

\section{Atribut Produk}

Menurut Kotler \& Armstrong (2018), atribut produk adalah pengembangan produk atau layanan yang melibatkan penentuan manfaat yang akan diberikan. Menurut Kotler \& Armstrong (2018) beberapa atribut yang menyertai dan melengkapi produk adalah:

1. Kualitas Produk (Product Quality)

Kualitas produk adalah salah satu alat penentuan posisi dasar bagi pemasar, lalu kualitas juga mempengaruhi kinerja produk atau layanan, oleh karena itu sangat erat kaitannya dengan nilai dan kepuasan pelanggan.

2. Fitur Produk (Product Features)

Sebuah produk dapat ditawarkan dengan berbagai macam fitur. Fitur adalah alat kompetitif yang dapat membedakan produk perusahaan dengan produk pesaing. 
3. Gaya dan Desain Produk (Product Style and Design)

Gaya dan desain produk yang khas adalah salah satu cara untuk menambah nilai kepada pelanggan. Desain memiliki konsep yang lebih besar daripada gaya, karena gaya hanya mendeskripsikan penampilan suatu produk saja.

Menurut Gito Sudarmo dalam (Pratiwi, 2017) atribut dari sebuah produk dapat berupa sesuatu yang memiliki wujud (tangible) ataupun sesuatu yang tidak memiliki wujud (ingtangible). Atribut produk yang memiliki wujud biasanya adalah merek, kualitas produk, desain produk, label produk, kemasan dan sebagainya. Sedangkan atribut yang tidak memiliki wujud biasanya berupa kesan atau image konsumen terhadap nama merek yang diberikan kepada produk tersebut.

Menurut Rahman et al., (2010) atribut produk untuk celana denim mencakup model, bahan, warna, lebar bukaan kaki. Sebagai tambahan Wu (2016) memasukkan arcuate sebagai salah satu indikator. Oleh kaerna itu, dalam penelitian ini menggunakan beberapa pengukuran seperti Model, Warna, Bahan, Waistline, dan Arcuate.

\section{Preferensi Konsumen}

Preferensi konsumen dapat diketahui dengan memperkirakan setiap atribut yang ada pada produk dapat diukur dengan tingkat kgunaan serta nilai yang relative penting(Ramadhani et al., 2020). atribut dalam sebuah produk atau jasa dapat menarik konsumen serta mempengaruhi keputusan pembelian konsumen. Penilaian terhadap suatu produk atau jasa oleh konsumen dapat menggambarkan sikap konsumen terhadap produk atau jasa tersebut, serta dapat mencerminkan perilaku konsumen dalam menggunakan produk atau jasa tersebut(Irawati et al., 2016).

Menurut (Kotler \& Armstrong, 2018) preferensi konsumen merupakan hal yang menunjukkan kesukaan konsumen terhadap sebuah produk atau jasa. Preferensi merupakan kesukaan (kecenderungan hati) kepada sesuatu. Preferensi dapat diartikan juga sebagai suka atau tidak suka konsumen terhadap produk atau jasa yang digunakannya. Abdul Rahman Shaleh dan Muhbib Abdul Wahab dalam (Wardhani et al., 2016) mendefinisikan preferensi itu dapat diartikan sebagai kecenderungan dalam memberikan perhatian terhadap seorang atau barang yang disertai dengan perasaan senang dan puas.

Menurut (Negeri \& Andriyanty 2020) preferensi konsumen dapat diartikan sebagai selera subyektif pada setiap individu yang diukur menggunakan tingkat kegunaan dari konsumsi produk atau jasa, hal ini juga memberikan kekuasaan atas konsumen untuk memberikan peringkat atas produk atau jasa dan harus dipastikan pula preferensi konsumen tidak bergantung kepada pendapatan (harga). Preferensi konsumen juga mempunyai kemampuan untuk dapat memberikan pengaruh terhadap pembelian oleh konsumen.

Menurut Hartalita \& Sharif (2017) Preferensi konsumen merupakan sikap dari suatu konsumen terhadap memilih pilihan terhadap merek produk yang terbentuk melalui evaluasi atas berbagai macam merek yang tersedia dan preferensi konsumen didefinisikan sebagai selera subyektif (individu), yang diukur dengan tingkat kegunaan atas konsumsi produk atau jasa. Teori ini memberikan kuasa pada konsumen untuk memberi peringkat atas produk atau jasa tersebut. Dan harus dipastikan bahwa bahwa preferensi konsumen tidak tergantung pada pendapatan dan harga. Kemampuan untuk 
membeli barang tidak menentukan suka atau tidak suka konsumen.

\section{Conjoint Analysis}

Apriyanti (2015) mengemukakan ukuran nilai dari analisis conjoin bersifat subjektif judgment serta unik dari setiap individu. Analisis konjoin mengharuskan peneliti menggabungkan level dari setiap atribut untuk membangun sebuah produk atau jasa. Jadi pada intinya analisis konjoin digunakan untuk mengetahui bagaimana preferensi responden terhadap satu objek yang terdiri atas satu atau banyak bagian. Didalam riset pemasaran analisis konjoin digunakan untuk mengetahui bagaimana preferensi konsumen terhadap berbagai desain produk.

Menurut Malhotra et al. (2017) conjoint analysis adalah sebuah metode yang berguna untuk menentukan kepentingan konsumen yang melekat pada atribut. Pada dasarnya, tujuan dari conjoint analysis sendiri adalah untuk mengetahui bagaimana preferensi seseorang terhadap suatu hal yang terdiri dari satu atau lebih.

Menurut Hair (2019) conjoint analysis adalah sebuah teknik multivariat yang dibuat secara khusus untuk memahami bagaimana responden mengembangkan preferensi dari semua jenis objek (produk, layanan, atau ide), keluaran dari conjoint analysis adalah sebuah atribut pada produk, jasa, atau objek tertentu yang sebagian besar diinginkan oleh konsumen, didalam melakukan analisis konjoin memerlukan responden yang memberikan informasi tambahan dari preferensi konsumen. Menurut (Malhotra et al., 2017), conjoint analysis bertujuan untuk menentukan kepentingan relatif dari atribut dalam proses pilihan konsumen, memperkirakan pangsa pasar merek yang berbeda di tingkat atribut, menentukan komposisi atribut yang paling disukai, dan mengelompokkan pasar berdasarkan kesamaan preferensi untuk tingkat atribut.

- Merumuskan Masalah

- Membentuk Stimulus

- Menentukan Bentuk Input Data

- Mengolah data dengan conjoint analysis

- Menginterprestasikan Hasil

- Mengukur Validitas

\section{METODE PENELITIAN}

\section{Jenis Penelitian}

Metode dalam penelitian ini menggunakan pendekatan kuantitatif dengan menggunakan metode Conjoint Analysis (Apriyanti, 2015). Ukuran nilai dari analisis conjoin bersifat subjektif judgment serta unik dari setiap individu. Analisis konjoin mengharuskan peneliti menggabungkan level dari setiap atribut untuk membangun sebuah produk atau jasa. Jadi pada intinya analisis konjoin digunakan untuk mengetahui bagaimana preferensi responden terhadap satu objek yang terdiri atas satu atau banyak bagian. Didalam riset pemasaran analisis konjoin digunakan untuk mengetahui bagaimana preferensi konsumen terhadap berbagai desain produk. Menurut Hair (2019) conjoint analysis adalah sebuah teknik multivariat yang dibuat secara khusus untuk memahami bagaimana responden mengembangkan preferensi dari semua jenis objek (produk, layanan, atau ide), keluaran dari conjoint analysis adalah sebuah atribut pada produk, jasa, atau objek tertentu yang sebagian besar diinginkan oleh konsumen, didalam melakukan analisis konjoin memerlukan responden yang memberikan informasi tambahan dari preferensi konsumen. Menurut (Malhotra et al., 2017), conjoint analysis bertujuan untuk menentukan kepentingan relatif dari atribut dalam proses pilihan konsumen, 
memperkirakan pangsa pasar merek yang berbeda di tingkat atribut, menentukan komposisi atribut yang paling disukai, dan mengelompokkan pasar berdasarkan kesamaan preferensi untuk tingkat atribut.

\section{Populasi dan Sampel}

Penetuan Teknik sampling dan jumlah sampel yang digunakan pada penelitian kali ini adalah non-probability sampling dengan memakai snowball sampling. Dengan menggunakan teknik ini makan akan memilih responden awal secara acak dan selanjutnya akan dipilih berdasarkan referensi atau informasi yang diberikan pada responden awal (Malhotra et al., 2017). Penelitian ini adalah jenis multivarat sehingga jumlah sampel harus diantara 100200 responden sehingga untuk jumlah sampel yang diperlukan adalah $10 \times 16=$ 160 responden dengan $\mathrm{n}$ adalah jumlah stimulu.

\section{Perancangan Kuesioner}

Pada perancangan desain kuesioner terbagi menjadi 3 bagian yang akan diisi oleh responden. Untuk bagian pertama adalah screening question, pada bagian ini terdapat pertanyaan yang akan memastikan apakah responden merupakan konsumen yang pernah membeli dan menggunakan produk celana denim dari Bobbiesjeans.co atau bukan, jika responden menjawab tidak, maka responden akan diarahkan ke halaman akhir dari kuesioner yang dalam artian tidak dapat mengisi kuesioner ini. Pada bagian kedua yaitu mengenai biodata dan karakteristik responden, pertanyaan ini dibuat untuk mengetahui karakteristik dari setiap responden. Dan pada bagian ketiga terdapat hasil kombinasi dari setiap atribut dan level atribut atau stimulus yang akan dinilai oleh responden dengan memberikan rating menggunakan plan card yang menggunakan skala (1) Sangat Tidak Suka, (2) Tidak Suka, (3)Suka, (4)Sangat Suka (Lutfiani et al., 2017).

\section{Metode Pengumpulan Data}

Perolehan data didapat dari hasil penyebaran kuisioner secara online dengan respondennya adalah konsumen Bobbiesjeans.co yang masih remaja hingga dewasa.

Setelah melakukan perancangan desain kuesioner, maka berikutnya adalah melakukan penyebaran kuesioner secara online dengan menggunakan bantuan Google Form agar dapat memudahkan dalam menjangkau responden dan memudahkan responden untuk mengisi kuesioner. Sesuai dengan bab sebelumnya, ukuran sample yang dibutuhkan pada penelitian ini sebanyak 160 responden, lalu bentuk plan card yang digunakan pada kuesioner dapat dilihat pada Gambar 1 .

\section{Analisis Data}

Setelah data tersebar kepada responden, berikutnya dilakukan pengumpulan data kuesioner, dimana data yang sudah terkumpul akan diolah menggunakan conjoint analysis. Pada tahap pertama, semua data yang sudah didapatkan dari hasil penyebaran kuesioner dilanjutkan dengan input data menggunakan bantuan software Microsoft Excel 2016. Selanjutnya Data yang telah di input akan memasuki tahap pengolahan data melalui software SPSS dengan menggunakan Conjoint Analysis. Conjoint Analysis digunakan untuk mengetahui nilai dari skor utilitas, importance values, dan predictive accuracy yang dianggap penting bagi konsumen celana denim Bobbiesjeans.co 


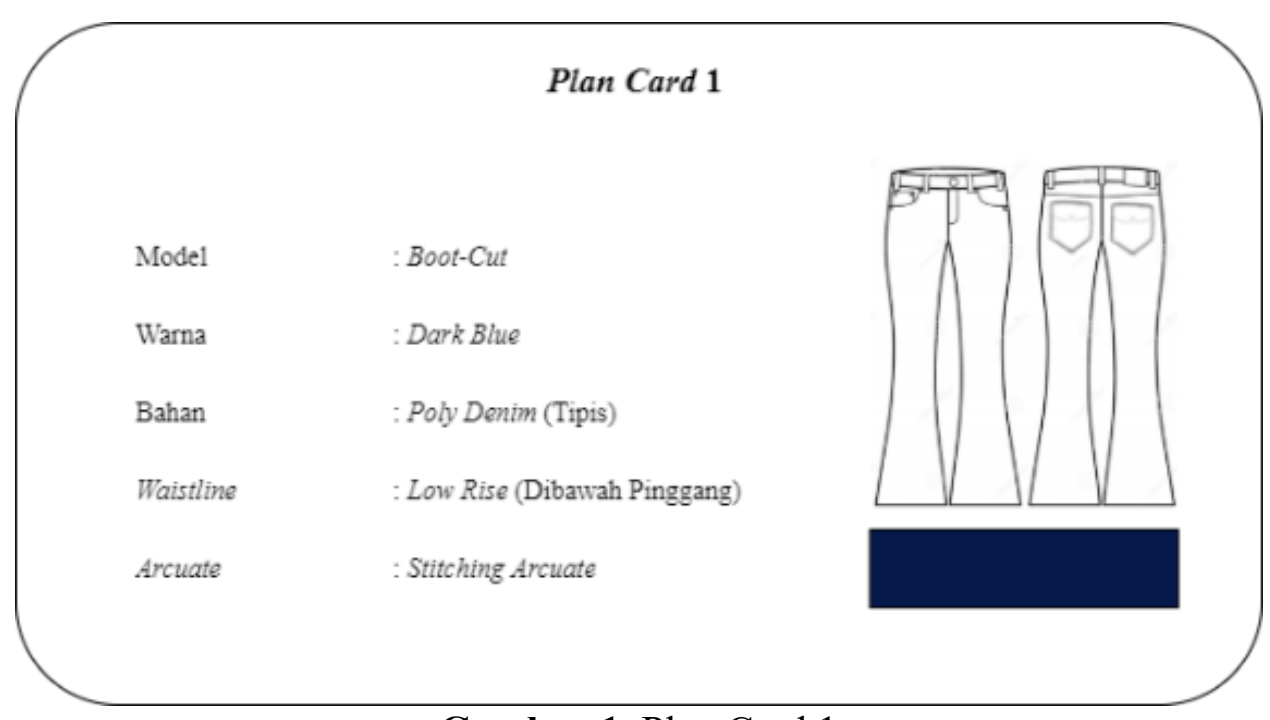

Gambar 1. Plan Card 1

Tabel 1. Rincian kuesioner Plan Card

\begin{tabular}{|c|c|c|c|c|c|}
\hline No Kartu & Model & Warna & Bahan & Waistline & Arcuate \\
\hline 1 & Boot-Cut & Dark Blue & Poly Denim & Low Rise & Stitching Arcuate \\
\hline 2 & Boot-Cut & Light Blue & Raw Denim & High Rise & Hidden Arcuate \\
\hline 3 & Regular Fit & Dark Blue & $\begin{array}{c}\text { Twill Fabric } \\
\text { Denim }\end{array}$ & Low Rise & Hidden Arcuate \\
\hline 4 & Slim Fit & Light Blue & Raw Denim & Low Rise & Stitching Arcuate \\
\hline 5 & Regular Fit & Dark Blue & Raw Denim & Mid Rise & Hidden Arcuate \\
\hline 6 & Regular Fit & Light Blue & Poly Denim & Mid Rise & Stitching Arcuate \\
\hline 7 & Regular Fit & Light Blue & Poly Denim & Low Rise & Stitching Arcuate \\
\hline 8 & Regular Fit & Black & Raw Denim & Low Rise & Stitching Arcuate \\
\hline 9 & Regular Fit & Black & $\begin{array}{c}\text { Twill Fabric } \\
\text { Denim }\end{array}$ & High Rise & Stitching Arcuate \\
\hline 10 & Boot-Cut & Black & Poly Denim & Low Rise & Hidden Arcuate \\
\hline 11 & Slim Fit & Black & Poly Denim & Mid Rise & Hidden Arcuate \\
\hline 12 & Slim Fit & Light Blue & $\begin{array}{l}\text { Twill Fabric } \\
\text { Denim }\end{array}$ & Low Rise & Hidden Arcuate \\
\hline 13 & Boot-Cut & Light Blue & $\begin{array}{c}\text { Twill Fabric } \\
\text { Denim }\end{array}$ & Mid Rise & Stitching Arcuate \\
\hline 14 & Regular Fit & Light Blue & Poly Denim & High Rise & Hidden Arcuate \\
\hline 15 & Regular Fit & Light Blue & Poly Denim & Low Rise & Hidden Arcuate \\
\hline 16 & Slim Fit & Dark Blue & Poly Denim & High Rise & Stitching Arcuate \\
\hline
\end{tabular}




\section{HASIL DAN PEMBAHASAN}

\section{Hasil}

Data yang telah di input akan memasuki tahap pengolahan data melalui software SPSS dengan menggunakan Conjoint Analysis. Conjoint Analysis digunakan untuk mengetahui nilai dari skor utilitas, importance values, dan predictive accuracy yang dianggap penting bagi konsumen celana denim Bobbiesjeans.co, maka didapatkan hasil seperti pada Tabel 2.

Berdasarkan Tabel 2 maka diketahui skor utilitas dengan menggunakan conjoint analysis. Skor utilitas diatas itu berfokus pada level atribut, dimana nilai yang semakin positif akan semakin besar juga ketertarikan dan keinginan responden, sedangkan jika nilai semakin negatif maka akan semakin kecil nilai ketertarikan atau keinginan pada responden. Pada tabel diatas memperlihatkan bahwa dari ketiga level atribut model yang memiliki nilai positif hanya boot-cut saja dengan nilai utilitas sebesar 0.016, sedangkan untuk model regular fit sebesar -0.007 dan slim fit memiliki nilai utilitas sebesar -0.009 . Sehingga dapat diketahui bahwa pilihan responden yang paling disukai adalah model celana denim dengan boot-cut.

Pada atribut warna yang memiliki nilai utilitas positif adalah light blue dan black, dengan nilai utilitas dari light blue sebesar 0.008 dan nilai utilitas dari level atribut black sebesar 0.006, sedangkan pada level atribut dark blue memiliki nilai utilitas negatif dengan nilai utilitas sebesar -0.013 . Sehingga dapat diketahui bahwa pilihan responden yang paling disukai adalah light blue dan black.

Atribut ketiga adalah bahan, lalu yang memiliki nilai utilitas positif pada atribut bahan adalah poly denim dengan nilai utilitas sebesar 0.088 sedangkan untuk level atribut raw denim memiliki nilai utilitas sebesar -0.039 dan untuk level atribut twill- fabric denim memiliki nilai utilitas sebesar 0.048. Sehingga pilihan respoden yang paling disukai adalah level atribut poly denim.

Pada atribut ke empat dapat dilihat pada atribut waistline yang memiliki nilai utilitas positif adalah low rise dan mid rise dengan nilai utilitas dari low rise sebesar 0.037 , lalu untuk nilai utilitas dari mid rise sebesar 0.018 , sedangkan pada level atribut high rise memiliki nilai utilitas yang negatif, yaitu dengan nilai sebesar -0.055 . Sehingga dapat diketahui bahwa pilihan responden yang paling disukai adalah low rise dan mid rise.

Selanjutnya pada atribut terakhir yaitu arcuate yang memiliki nilai utilitas positif pada level atributnya adalah stitching arcuate dengan nilai utilitas sebesar 0.013, sedangkan untuk hidden arcuate memiliki nilai utilitas sebesar $-0,013$. Sehingga pilihan responden yang paling disukai adalah hidden arcuate.

Hasil dari pengujian importance values pada Tabel 3 memperlihatkan nilai dari kepentingan setiap atribut. Pada importance values ini lebih difokuskan kepada atribut. Dapat dilihat bahwa warna merupakan atribut terpenting dengan nilai sebesar 23.177, lalu pada atribut lainnya memiliki nilai dibawah dari atribut warna. Selanjutnya pada urutan kedua pada importance values adalah atribut bahan dengan nilai sebesar 22.430. Urutan ketiga yaitu atribut waistline dengan nilai kepentingan sebesar 22.007. Urutan keempat yaitu atribut Model dengan nilai kepentingan sebesar 21.197. Dan urutan terakhir adalah atribut dari arcuate dengan nilai kepentingan sebesar 11.190.

Terakhir pengujian dari predictive accuracy yang ditunjukkan pada Tabel 4, berdasarkan perhitungan dengan menggunakan IBM SPSS 25.0. Diketahui terdapat 2 output yaitu, Pearson's R dan Kendall's tau. Dikarenakan bentuk input data pada 
penelitian ini berupa data metrik yang menggunakan rating, maka output yang digunakan adalah Pearson's R dengan nilai sebesar 0.809 .

Tabel 2. Skor Utilitas

\begin{tabular}{|l|l|l|l|}
\hline \multirow{4}{*}{ Model } & Regular Fit & Utility Estimate & Std. Error \\
\cline { 2 - 4 } & Slim Fit & -.007 & .031 \\
\cline { 2 - 4 } & Boot-Cut & -.009 & .036 \\
\hline Warna & Light Blue & .016 & .036 \\
\cline { 2 - 4 } & Dark Blue & .008 & .031 \\
\cline { 2 - 4 } & Black & -.013 & .036 \\
\hline Bahan & Poly Denim & .006 & .036 \\
\cline { 2 - 4 } & Raw Denim & .088 & .031 \\
\cline { 2 - 4 } & Twill Fabric Denim & -.039 & .036 \\
\hline Waistline & Low Rise & .037 & .036 \\
\cline { 2 - 4 } & Mid Rise & .018 & .036 \\
\cline { 2 - 4 } & High Rise & -.055 & .036 \\
\hline \multirow{3}{*}{ Arcuate } & Hidden Arcuate & -.013 & .023 \\
\cline { 2 - 4 } & Stitching Arcuate & .013 & .028 \\
\hline (Constant) & & 2.652 & \\
\hline
\end{tabular}

Tabel 3. Importance Values Atribut

\begin{tabular}{|c|l|c|c|}
\hline Atribut & Level Atribut & Utility & Importance Values \\
\hline \multirow{4}{*}{ Warna } & Light Blue & -0.007 & \multirow{2}{*}{23.192} \\
\cline { 2 - 3 } & Dark Blue & -0.009 & \\
\cline { 2 - 3 } & Black & 0.016 & \\
\hline \multirow{4}{*}{ Bahan } & Poly Denim & 0.008 & \multirow{2}{*}{22.430} \\
\cline { 2 - 3 } & Raw Denim & -0.013 & \multirow{2}{*}{22.007} \\
\cline { 2 - 3 } & Twill Fabric Denim & 0.006 & \\
\hline \multirow{7}{*}{ Waistline } & Low Rise & 0.088 & \multirow{2}{*}{21.197} \\
\cline { 2 - 3 } & Mid Rise & -0.039 & \\
\cline { 2 - 3 } & High Rise & -0.048 & \\
\hline \multirow{2}{*}{ Model } & Regular Fit & 0.037 & \multirow{2}{*}{11.190} \\
\cline { 2 - 3 } & Slim Fit & 0.018 & \\
\cline { 2 - 3 } & Boot-Cut & -0.055 & \\
\hline Arcuate & Hidden Arcuate & -0.013 & \\
\cline { 2 - 3 } & Stitching Arcuate & 0.013 & \\
\hline
\end{tabular}

Tabel 4. Nilai Predictive Accuracy

\begin{tabular}{|l|l|l|}
\hline & Value & Sig. \\
\hline Pearson's R & .809 & .000 \\
\hline
\end{tabular}




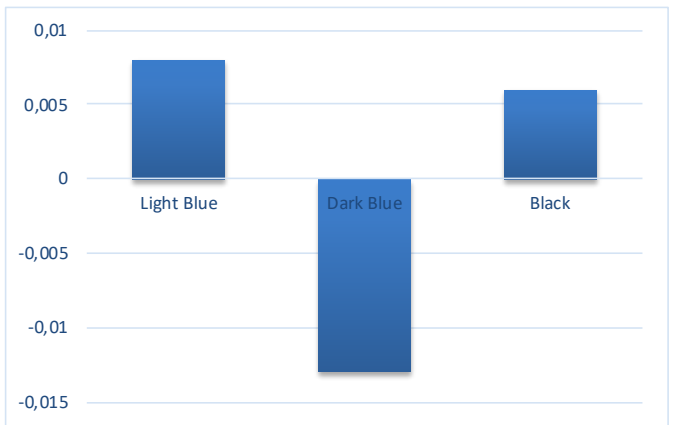

Gambar 2. Skor Utilitas Warna

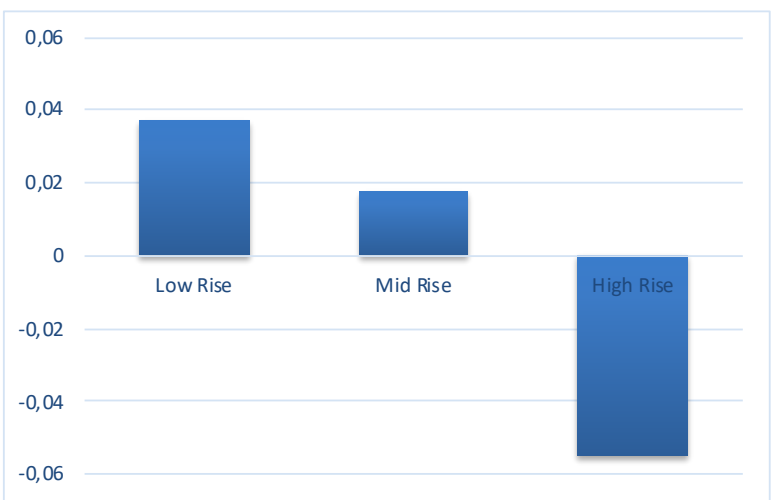

Gambar 4. Skor Utilitas Waistline

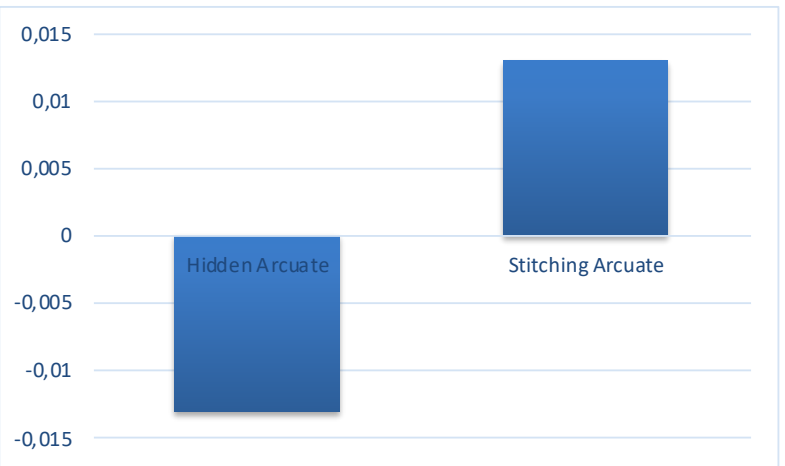

Gambar 6. Skor Utilitas Arcuate

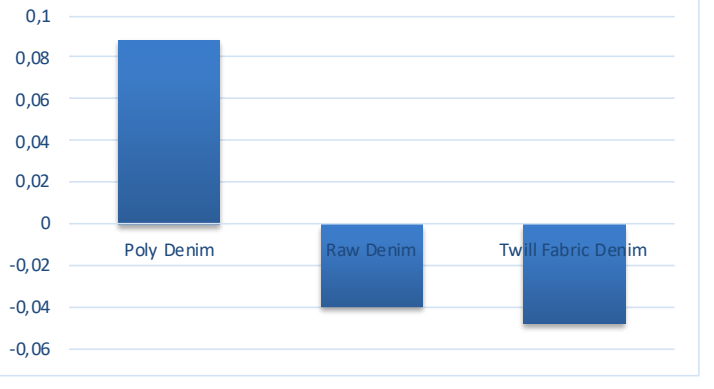

Gambar 3. Skor Utilitas Bahan

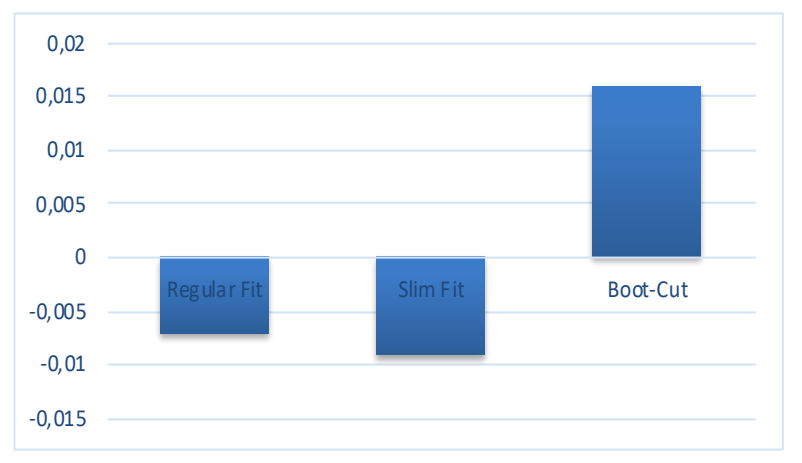

Gambar 5. Skor Utilitas Model

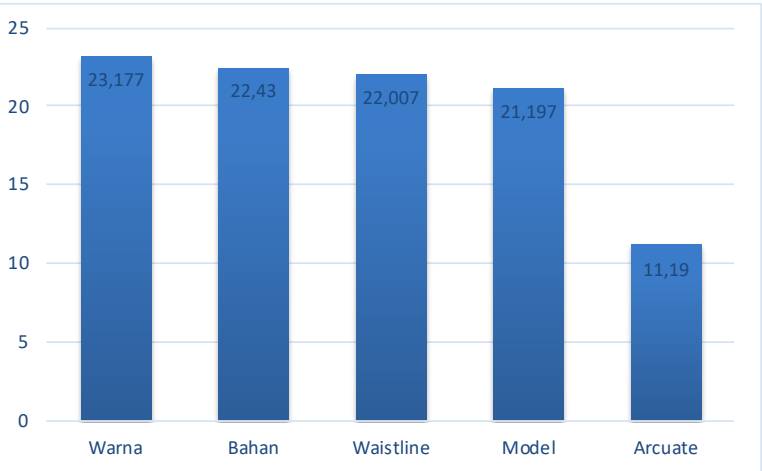

Gambar 7. Importance Values

\section{Pembahasan}

Berdasarkan hasil yang telah diperoleh dari penelitian ini, maka didapatkan kesimpulan yang sesuai dengan tujuan penelitian sebagai berikut.

Berdasarkan perhitungan menggunakan conjoint analysis terdapat 5 preferensi konsumen celana denim Bobbiesjeans.co, yaitu atribut warna dengan level atribut light blue dan black, atribut bahan dengan level atribut poly denim (12 oz), atribut waistline dengan level atribut low rise (dibawah

pinggang) dan mid rise (dipinggang), atribut model dengan level atribut boot-cut, atribut arcuate dengan level atribut stitching arcuate. Berdasarkan penelitian yang sudah dilakukan, terdapat perbandingan antara atribut eksisting Bobbiesjeans.co dengan preferensi konsumen. Untuk atribut warna pada eksisting celana denim Bobbiesjeans.co adalah black dan dark blue, sedangkan untuk preferensi konsumen yaitu light blue dan black. Untuk atribut bahan pada eksisting celana denim Bobbiesjeans.co adalah raw 
denim (14 oz) dan Twill Fabric Denim (16 oz), sedangkan berdasarkan preferensi konsumen yaitu poly denim $(12 \mathrm{oz})$. Konsumen lebih memilih bahan dengan poly denim sebagai preferensi, dikarenakan pada bahan tersebut lebih condong ke tipis, karena bahan tersebut lebih elastis dan tidak panas ketika digunakan. Hal tersebut sesuai dengan yang dikemukakan oleh (Miller, 2015) yang menyatakan bahan poly denim cocok digunakan untuk bahan pembuatan celana jeans karena bahan tersebut cendurung elastis dan lebih tipis.

Untuk atribut waistline pada eksisting celana denim Bobbiesjeans.co adalah high rise (diatas pinggang), sedangkan untuk preferensi konsumen yaitu low rise (dibawah pinggang) dan mid rise (dipinggang). ernyataan tersebut sejalan dengan penelitian yang dilakukan (Cho \& Chu, 2018) yang mngatakan bahwa waistline yang cocok digunakan saat bekerja adalah yang berada dipinggang.

Selanjutnya untuk atribut model pada eksisting Bobbiesjeans.co adalah regular fit dan slim fit, sedangkan untuk preferensi konsumen yaitu boot-cut. Pernyataan tersebut bertentangan dengan penelitian yang dilakukan (Dhouib et al., 2016) bahwa gaya celana yang cocok digunakan adalah model Boot-cut.

Dan untuk atribut arcuate pada eksisting Bobbiesjeans.co adalah hidden arcuate, sedangkan untuk preferensi konsumen adalah stitching arcuate. Pernyataan tersebut sejalan dengan penelitian (Abrego, 2021) yang menyatakan stitching arcuate lebih disukai oleh konsumen celana denim di amerika.

Berdasarkan hasil perbandingan pada penelitian yang sudah dilakukan, untuk warna dapat ditambahkan warna light blue. Untuk bahan perlu ditambah variasi bahan poly denim (12 oz). Selanjutnya untuk waistline juga perlu ditambahkan variasi low rise (dibawah pinggang) dan mid rise (dipinggang). Berikutnya untuk model perlu ditambah variasi model boot-cut. Dan untuk arcuate juga perlu ditambahkan variasi stitching arcuate.

\section{KESIMPULAN DAN SARAN}

\section{Kesimpulan}

Industri fashion saat ini berkembang dengan pesat, dan semua orang, terutama kaum muda, sangat antusias dengan hal itu. Sulit bagi pengusaha fashion untuk sukses. Ada persaingan karena ada begitu banyak pesaing. Preferensi konsumen akan selalu berubah, dan perubahan cepat dalam preferensi konsumen berdampak signifikan terhadap pertumbuhan industri gaya hidup. Oleh karena itu, tujuan dari penelitian ini adalah untuk menentukan preferensi konsumen terhadap atribut produk Bobbijeans.co. Terdapat perbandingan antara atribut yang ada pada Bobbiesjeans.co dengan preferensi konsumen berdasarkan penelitian yang telah dilakukan. Celana denim Bobbiesjeans.co yang ada memiliki atribut warna hitam dan biru tua, sedangkan pelanggan lebih menyukai warna biru muda dan hitam. Raw denim dan Twill Fabric Denim adalah atribut material dari celana denim Bobbiesjeans.co yang ada, sedangkan poly denim lebih disukai oleh pelanggan. Celana denim Bobbiesjeans.co yang ada memiliki garis pinggang yang tinggi, sedangkan preferensi pelanggan lebih menyukai low rise dan mid rise. Warna biru muda dapat ditambahkan berdasarkan hasil perbandingan pada penelitian yang telah dilakukan. Variasi bahan poly denim diperlukan untuk bahan tersebut. Juga perlu untuk memasukkan variasi low rise dan mid rise untuk lingkar pinggang.

\section{Saran}

Seperti yang telah dijelaskan, penelitian ini berfokus pada identifikasi preferensi konsumen terkait dengan atribut produk 
celana jeas di Bobbijeans.co. Penelitian di masa mendatang dapat memastikan lebih lanjut tentang keberadaan dari atribut tersebut dengan melakukan penelitian terhadap atribut produk dan pengaruhnya terhadap kepuasan pelanggan. Selanjutnya penelitian ini dilakukan di Kota Bandung dengan kriteria udara yang relative dingin. Penelitian di masa mendatang dapat mempertimbangkan perbedaan daerah dengan kriteria suhu yang berbeda.

\section{DAFTAR PUSTAKA}

Abrego, S. (2021). From Cattle Brand to Corporate Brand: Blue Jean Trademarks in Mid-century America. Journal of Design History. https://doi.org/10.1093/jdh/epab007

Angela, V., \& Paramita, E. L. (2020). PENGARUH LIFESTYLE DAN KUALITAS PRODUK TERHADAP KEPUTUSAN IMPULSE BUYING KONSUMEN SHOPEE GENERASI Z. Jurnal Ekobis: Ekonomi Bisnis \& Manajemen.

https://doi.org/10.37932/j.e.v10i2.132

Apriyanti, A. (2015). Analisis Conjoint Preferensi Konsumen terhadap Kombinasi Fitur Produk Motor Bekas Berdasarkan Segmen Gender di Jambi. The Winners. https://doi.org/10.21512/tw.v14i2.638

Cho, H. W., \& Chu, C. (2018). Watch your waistline. In Osong Public Health and Research Perspectives. https://doi.org/10.24171/j.phrp.2018.9.2. 01

Dhouib, S., Khedher, F., \& Sakli, F. (2016). A new approach to predict the fabric shrinkage in denim garments after finishing treatments. Journal of the Textile Institute. https://doi.org/10.1080/00405000.2015.1 034928
Disler, R. T., Gallagher, R. D., Davidson, P. M., Sun, S.-W., Chen, L.-C., Zhou, M., Wu, J.-H., Meng, Z.-J., Han, H.-L., Miao, S.-Y., Zhu, C.-C., Xiong, X.-Z., Reis, M. S., Sampaio, L. M. M., Lacerda, D., De Oliveira, L. V. F., Pereira, G. B. M., Pantoni, C. B. F., Di Thommazo, L., ... Mistraletti, G. (2019). Factors impairing the postural balance in COPD patients and its influence upon activities of daily living. European Respiratory Journal.

Fathurahman, F., Rohayati, Y., Pratami, D., Industri, F. R., Telkom, U., K-lite, R., \& Masyarakat, P. (2017). Perancangan Atribut Program Radio K-lite Fm Berdasarkan Preferensi Masyarakat Bandung Dengan Menggunakan Metode Conjoint Analysis. EProceedings of Engineering.

Hair. (2019). Multivariate Data Analysis. In Mathematics of Computation (Vol. 50, Issue

181). https://doi.org/10.2307/2007941

Hameed, W. U., Nisar, Q. A., \& Wu, H. C. (2021). Relationships between external knowledge, internal innovation, firms' open innovation performance, service innovation and business performance in the Pakistani hotel industry. International Journal of Hospitality Management. https://doi.org/10.1016/j.ijhm.2020.1027 45

Hartalita, L., \& Sharif, O. O. (2017). ANALISIS PREFERENSI KONSUMEN MUDA TERHADAP IPHONE DI KOTA BANDUNG Abstrak Pendahuluan. 3(2), 105-113.

Irawati, D. Y., Singgih, M. L., \& Syarudin, B. (2016). Integrasi Quality Function Deployment (QFD) dan Conjoint Analysis untuk Mengetahui Preferensi Konsumen. Jurnal Optimasi Sistem Industri.

https://doi.org/10.25077/josi.v13.n2.p61 $8-640.2014$ 
Kotler, P., \& Armstrong, G. (2018). Kotler \&amp; Armstrong, Principles of Marketing | Pearson. In Pearson.

Lestiyorini, D. (2015). Model Analisis Pengembangan Produk Baru Obat Herbal di Indonesia Dengan Mempertimbangkan Preferensi Konsumen. In Journal of Chemical Information and Modeling.

Lutfiani, D., Romano, R., \& Kasimin, S. (2017). Preferensi Konsumen Terhadap Furnitur di Kota Banda Aceh. Jurnal Ilmiah Mahasiswa Pertanian. https://doi.org/10.17969/jimfp.v2i1.2271

Malhotra, N. K., Nunan, D., \& Birks, D. F. (2017). MARKETING (Fifth Edit). Pearson.

Miller, D. (2015). Denim. Consumption Markets and Culture. https://doi.org/10.1080/10253866.2015.1 008193

Negeri, D., \& Andriyanty, R. (2020). Preferensi Konsumen Generasi Z terhadap Konsumsi Produk Dalam Negeri. February. https://doi.org/10.29313/ethos.v7i2.4694

Pradana, M., \& Reventiary, A. (2016). PENGARUH ATRIBUT PRODUK TERHADAP KEPUTUSAN PEMBELIAN SEPATU MEREK CUSTOMADE (STUDI di MEREK DAGANG CUSTOMADE INDONESIA). Jurnal Manajemen. https://doi.org/10.26460/jm.v6i1.196

Pratiwi, A. L. (2017). Pengaruh Gaya hidup, Citra Merek, dan Atribut Produk, terhadap Keputusan Pembelian Hijab Zoya di Jakarta Selatan. Fakultas Ekonomi Dan Bisnis Universitas Islam Negeri Syarif Hidayatullah Jakarta.
Rahardjo, C. R. (2016). Faktor Yang Menjadi Preferensi Konsumen Dalam Membeli Produk Frozen Food. Jurnal Manajemendan Start-Up Bisnis.

Rahman, O., Jiang, Y., \& Liu, W. sun. (2010). Evaluative criteria of denim jeans: A cross-national study of functional and aesthetic aspects. Design Journal, 13(3), 291-312. https://doi.org/10.2752/146069210X127 66130824894

Ramadhani, F., Barokah, U., \& Sutrisno, J. (2020). ANALISIS PREFERENSI KONSUMEN TERHADAP PEMBELIAN TEH DI KABUPATEN SUKOHARJO. AGRISAINTIFIKA: Jurnal Ilmu-Ilmu Pertanian. https://doi.org/10.32585/ags.v4i1.838

Sutisna. (2003). Perilaku Konsumen: Teori dan penerapannya dalam Pemasaran. Ghalia Indonesia, Jakarta. https://doi.org/10.1007/BF01013984

Tjiptono, \& Fandy. (2015). Strategi Pemasaran. In Yogyakarta: Andi.

Wardhani, W., Sumarwan, U., \& Yuliati, L. N. (2016). Pengaruh Persepsi dan Preferensi Konsumen terhadap Keputusan Pembelian Hunian Green Product. Jurnal Manajemen Dan Organisasi.

https://doi.org/10.29244/jmo.v6i1.12183 Wirapraja, A., Sudarso, A., Mardia, M., Tojiri, M. Y., Simarmata, H. M. P., Sulasih, S., Permadi, L. A., Purba, B., Dwidienawati, D., Darwin, T., Lie, F., \& Manullang, S. O. (2021). Manajemen Pemasaran Perusahaan. In Yayasan Kita Menulis. 